\title{
Correlation of Anthropometric Indices with Blood Pressure - A Study in North Indian Females
}

\author{
Sandhya Singh ${ }^{1}$, Reena Singla ${ }^{2}$ \\ ${ }^{1}$ Department of Anatomy, MMIMSR, Mullana, Haryana, India. \\ ${ }^{2}$ Department of Anatomy, MMIMSR, Mullana, Haryana, India.
}

\section{ABSTRACT}

\section{BACKGROUND}

Several studies have shown a significant relationship between weight and high blood pressure. High blood pressure is correlated with overweight and obesity which can be assessed by anthropometric indices. Therefore, this study was undertaken to determine the predictors, and correlation of anthropometric indices with blood pressure among females.

\section{METHODS}

A cross sectional study was conducted among 300 females (25-40 years of age) of known endogamous groups baniyas and jats of Punjab. Measurements taken include systolic and diastolic blood pressure and anthropometric parameters such as height, weight, waist and hip circumference. Information was obtained about lifestyle and dietary habits. Data was statistically analysed.

\section{RESULTS}

Mean and standard deviation of BMI, WHR, SBP, DBP of Baniya was higher as compared to jats. $p$ value was statistically significant for height, SBP, DBP, HC, BMI and WHR. Overweight (53.2\%) and obesity (36\%) were seen in both groups. Derived anthropometric indices for example WC, WHtR and WHR were raised and prevalence of prehypertension was more in both endogamous groups. A positive correlation was observed between blood pressure and anthropometric indices with significant $p$ value.

\section{CONCLUSIONS}

BMI, WC and WHtR have a significant association with the risk of hypertension among females aged 25-40 years. Hence, approaches to reduce the risk of hypertension may include prevention of overweight and obesity in the form of diet education, weight monitoring and regular exercise.

\section{KEY WORDS}

Anthropometry, Blood Pressure, Baniya, Jats, Females, Waist Hip Ratio, Body Mass Index
Corresponding Author:

Dr. Reena Singla,

Hno.40, Raja Park,

Ambala Cantt,

133001, Haryana, India.

E-mail: singla.reena@ymail.com

DOI: $10.14260 /$ jemds/2020/211

Financial or Other Competing Interests: None.

How to Cite This Article:

Singh $S$, Singla $R$. Correlation of anthropometric indices with blood pressure- $a$ study in North Indian females. J. Evolution Med. Dent. Sci. 2020;9(12): 980-984, DOI: 10.14260/jemds/2020/211

Submission 20-01-2019,

Peer Review 03-03-2020,

Acceptance 09-03-2020,

Published 23-03-2020.

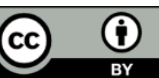




\section{BACKGROUND}

Despite the modern techniques, anthropometric measurements such as height, weight, Body Mass Index (BMI) and waist-hip circumference ratio (WHR) are traditionally important methods to study the genetic structure and prediction of risk factors of many complex diseases in human health. Anthropometric measurements have been the subjects of much epidemiologic and pathophysiologic research involving obesity, overweight, body fat distribution, and health outcomes. Anthropometry is the study of human body measurements. Anthropometric measurements are a set of non-invasive, quantitative techniques of determining an individual's body fat composition by measuring, recording and analysing specific dimensions of the body. Anthropometric indices such as body mass index (BMI) and waist circumference (WC) relate to important health outcomes which are easy and relatively inexpensive to measure and are easy to monitor over time by either the individuals themselves or their health care providers. ${ }^{1}$ The precise measurement of visceral fat requires the use of magnetic resonance imaging or tomography, which are scientific techniques that visually depicts the internal tissue compositions. Waist circumference (WC) is a substitute technique for these scientific assessments. A waist circumference more than 35 inches in women is associated with higher cardiometabolic risk. ${ }^{2}$

Partial correlation and co-variance analysis show that WC exhibit the highest degree of association with almost all of metabolic profiles for both men and women. There is significant gender differences in association between central or general obesity with cardiovascular risk factors. WHR are more strongly correlated with metabolic risks for women than men. The useful anthropometric predictors for cardiovascular risk factors are WC and WHR for women. ${ }^{3}$ Height does not importantly influence the difference in measures of adiposity or intra-abdominal fat volume in women, or intra-abdominal fat area in women and men. Age does influence the prediction of intra-abdominal fat from waist circumference, but waist circumference alone has a predictable simple relationship with intra-abdominal fat volume or area, which is likely to relate to the prediction of health risk for health promotion. ${ }^{4}$ Obesity is an independent risk factor for cardiovascular diseases as increased body fat is accompanied by changes in physiologic and metabolic functions of the body, which are directly dependent on the degree of excess weight and its distribution around the body. ${ }^{5}$ Hypertension is a global health problem affecting 26\%(1 billion) adult population worldwide in the year $2000^{6}$ and predicted to increase to 1.56 billion by $2025^{7}$. Previous studies have reported significant association between different anthropometric indicators and blood pressure levels ${ }^{8,9}$. BMI, WHR, WHtR have been used in various studies to analyse the association between adiposity and cardiovascular risk factors ${ }^{10,11}$ Although there are many anthropometric indices that have been used to measure obesity, there is a debate about which of the anthropometric indices best defines obesity and contributes to the highest risk for causing hypertension. ${ }^{12}$ However there is a dearth of literature on this type of study among the endogamous groups (baniyas and Jats) of north Indian females, particularly in Punjab. This study was therefore undertaken to determine the predictors and correlation of anthropometric indices with blood pressure among two endogamous groups of Punjab.

\section{METHODS}

A cross sectional study was conducted on 300 females (25-40 years of age) of known endogamous groups (baniya \& jats) of Punjab (in the year 2012-2014) at Department of Anatomy, MMIMSR, Mullana. The subjects were taken from the urban and rural population of Punjab. Persons with pregnancy, known hypertension, coronary artery disease, diabetes mellitus were excluded from the study. The study was approved by institutional ethical committee. The subjects were informed about the study, formal consent was taken from them and following anthropometric measurements were taken-

1. Height (in Centimeters): was measured with a flexible metallic measuring tape with the subject, standing barefooted in an erect position against an even wall or hard surface with the head positioned so that the top of the external auditory meatus was in level with the inferior margin of the bony orbit. ${ }^{13}$

2. Weight (in Kilograms): (to the nearest $0.5 \mathrm{Kg}$ ) was recorded with the subject standing motionless on the weighing scale, barefooted wearing minimum clothes and maintaining the privacy.

3. Circumferences: The waist and hip circumferences in centimeters were measured with a non-stretchable measuring tape. These circumferences were measured twice, to the nearest centimeter and the mean was used for subsequent analysis.

1. Waist circumference (cms) was measured by using bone landmarks as references. The WHO guidelines recommend the measurement of waist circumference at the mid-point between the lowest rib and the iliac crest (the highest point of the ilium)..$^{9}$ cut - off value for $\mathrm{WC}=80 \mathrm{~cm} \cdot{ }^{14}$

2. Hip circumference (cms) was measured at the level of the greater trochanters in centimeters. It should be taken around the widest portion of buttocks, with the tape parallel to the floor. ${ }^{15}$

Derived anthropometric indices were calculated as follows-

1. Body Mass Index (BMI): Weight (kgs)/height (m) ${ }^{2}$ ). Asian Pacific classification for BMI was applied to classify the studied population into the following:

1. Underweight $=<18.5 \mathrm{Kg} / \mathrm{m}^{2}$

2. Normal weight $=18.5-22.9 \mathrm{Kg} / \mathrm{m}^{2}$

3. Overweight $=\geq 23.0 \mathrm{Kg} / \mathrm{m}^{2}$

4. At risk $=23.0-24.9 \mathrm{Kg} / \mathrm{m}^{2}$

5. Obese $\mathrm{I}=25.0-29.9 \mathrm{Kg} / \mathrm{m}^{2}$

6. Obese II $=>30 \mathrm{Kg} / \mathrm{m}^{2}$

2. Waist-Hip Ratio (WHR): WHR = WC $(\mathrm{cm}) / \mathrm{HC}(\mathrm{cm})$ Cut-off value used was 0.81 .14

3. Waist-Height Ratio (WHtR): WHtR $=$ WC $(\mathrm{cm}) /$ Height (cm) Cut-off value used was 0.5.15 
4. Blood Pressure: A mercury-in-glass sphygmomanometer calibrated in millimetres of mercury from $0-300 \mathrm{mmHg}$ was used to measure the blood pressure of the participants to the nearest $1 \mathrm{~mm}$ of mercury with the aid of Littman stethoscope (USA). As per JNC (Joint National Committee) guidelines. ${ }^{16}$

- Normal - Systolic and Diastolic < 120/80 mmHg

- Prehypertension - Systolic 120-129; Diastolic 80-89 mmHg

- Hypertension (stage -1)- Systolic 140-159; Diastolic 90-99 of $\mathrm{mmHg}$

- (Stage -2)-systolic >160; Diastolic $>100$ mmHg

\section{Statistical Analysis}

For statistical analysis the data was imported in SPSS (statistical package for social sciences, version 16) and was analysed for descriptive frequency of all variables. Mean, standard deviation, t-test, Pearson's correlation coefficient, Logistic regression analysis ANOVA were used to investigate the relationship between anthropometric measurements and blood pressure among study groups. Multiple regression analysis was used to find the predictors for blood pressure from anthropometric variables. Probability value ( $\mathrm{p}$-value) $\leq$ 0.05 have been considered to be significant* and \& p-value $<0.001$ highly significant.**

\section{RESULTS}

\begin{tabular}{|cccc|}
\hline Variables & Baniya (n=150) & Jat $(\mathbf{n}=150)$ & p Value \\
Age & $31 \pm 5.4$ & $30.33 \pm 4.39$ & 0.2393 \\
Height $(\mathrm{cm})$ & $1.61 \pm 0.02$ & $1.62 . \pm 0.03$ & $0.001^{* * \mathrm{HS}}$ \\
weight & $61.48 \pm 4.73$ & $60.68 \pm 6.57$ & 0.2271 \\
SBP & $125 \pm 5.8$ & $123.06 \pm 6.26$ & $0.0057^{* * \mathrm{HS}}$ \\
DBP & $85 \pm 7.5$ & $82.91 \pm 5.69$ & $0.0069^{* * \mathrm{HS}}$ \\
WC & $85.04 \pm 9.35$ & $84.76 \pm 8.94$ & 0.7911 \\
HC & $90.43 \pm 9.4$ & $92.63 \pm 8.54$ & $0.0347^{*}$ \\
BMI & $23.18 \pm 1.99$ & $22.63 \pm 2.57$ & $0.0391^{*}$ \\
WHR & $0.93 \pm 0.01$ & $0.91 \pm 0.04$ & $0.0001^{* * \mathrm{H}}$ \\
WHTR & $0.52 \pm 0.06$ & $0.52 \pm 0.06$ & 1.0000 \\
\hline \multicolumn{4}{c}{ Table 1. Baseline Data of Study Population } \\
\hline ** p value highly significant at 0.001 level. ${ }^{*}$ p value significant at 0.05 \\
\hline \multicolumn{3}{c}{} \\
\hline
\end{tabular}

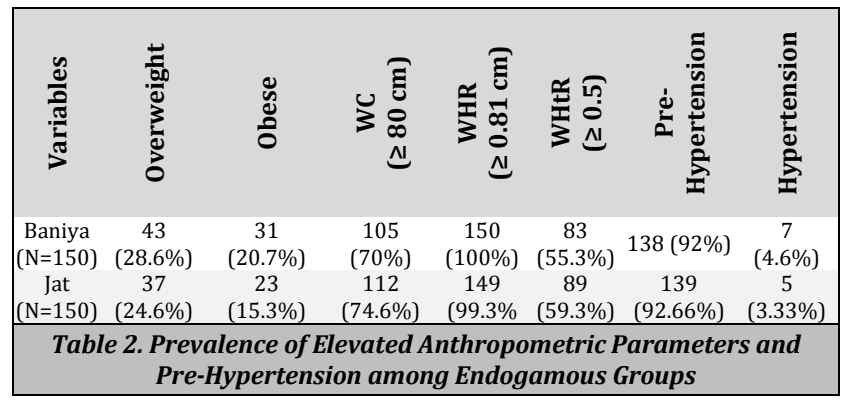

\begin{tabular}{|c|c|c|c|c|}
\hline \multirow{2}{*}{ Variables } & \multicolumn{2}{|c|}{ SBP } & \multicolumn{2}{|c|}{ DPB } \\
\hline & Jat & Baniya & Jat & Baniya \\
\hline Weight & $0.425^{* *}$ & $0.482^{* *}$ & $0.297^{* *}$ & $0.355^{* *}$ \\
\hline BMI & $0.347^{* *}$ & $0.438^{* *}$ & $0.298^{* *}$ & $0.377^{* *}$ \\
\hline WC & $0.389^{* *}$ & $0.487^{* *}$ & $0.317^{* *}$ & $0.345^{* *}$ \\
\hline WHR & $0.173^{*}$ & $0.326^{* *}$ & $0.187^{*}$ & $0.266^{* *}$ \\
\hline WHtR & $0.353^{* *}$ & $0.485^{* *}$ & $0.320^{* *}$ & $0.356^{* *}$ \\
\hline \multicolumn{5}{|c|}{$\begin{array}{c}\text { Table 3. Comparison of Correlation Coefficient of Anthropometric } \\
\text { Variables with Blood Pressure among Study Population }\end{array}$} \\
\hline
\end{tabular}

\begin{tabular}{|c|c|c|c|c|}
\hline Study Groups & Predictors & Regression Equation & $\mathbf{R}^{2}$ & p-value \\
\hline Baniya & WC & $\mathrm{Y}=0.3007 * \mathrm{X}+99.80$ & 0.237 & $<0.0001$ \\
\hline Jats & BMI & $\mathrm{Y}=0.8471 * \mathrm{X}+104.6$ & 0.121 & $<0.0001$ \\
\hline \multicolumn{5}{|c|}{$\begin{array}{l}\text { Table 4. Regression Analysis of Different Anthropometric Variables } \\
\text { with Systolic Blood Pressure among Study Groups }\end{array}$} \\
\hline \multicolumn{5}{|c|}{$\begin{array}{l}\text { p-value highly significant at } 0.0001 . Y=\text { systolic blood pressure; } R=\text { Regression } \\
\text { equation; } X=\text { Predictors, } p=\text { probability }\end{array}$} \\
\hline
\end{tabular}

\begin{tabular}{|c|c|c|c|c|}
\hline Study Group & Predictors & Regression Equation & $\mathbf{r}^{2}$ & p value \\
\hline & WHtR & $\mathrm{Y}=33.04 * \mathrm{X}+66.22$ & 0.102 & $<0.0001$ \\
\hline Baniya & WC & $\mathrm{Y}=0.4320 * \mathrm{X}+48.98$ & 0.288 & $<0.0001$ \\
\hline \multicolumn{5}{|c|}{$\begin{array}{l}\text { Table 5. Regression Analysis of Different Anthropometric Variables } \\
\text { with Diastolic Blood Pressure among Study Groups }\end{array}$} \\
\hline \multicolumn{5}{|c|}{$\begin{array}{l}{ }^{*} \mathrm{p} \text { value significant at } 0.0001 \\
\mathrm{Y}=\text { diastolic blood pressure, } \mathrm{R}=\text { Regression equation and } \\
\mathrm{X}=\text { Predictors, } \mathrm{p}=\text { probability }\end{array}$} \\
\hline
\end{tabular}

Mean and standard deviation of BMI, WHR, SBP, DBP of Baniya was higher as compared to jats. $p$ value was statistically significant for height, SBP, DBP, HC, BMI and WHR. (Table-1)Overweight (53.2\%) and obesity (36\%) were seen in both groups. Derived anthropometric indices for example WC, WHtR and WHR were raised among and prevalence of prehypertension is more in both endogamous groups. (Table - 2)A strong positive correlation was observed between blood pressure and anthropometric indices. (Table3)BMI and WHtR was found to be significant predictor for SBP and DBP in jats whereas WC had a significant predictability for both SBP and DBP in baniya. (Table-4, 5)

\section{DISCUSSION}

On comparison among two study groups (baniya, jats) it was found that mean and standard deviation for BMI, WHR, systolic and diastolic blood pressure (DBP) is more. (Table-1). Prevalence of overweight (53.2\%) and obesity (36\%) are seen in both endogamous groups. However, prevalence of elevated anthropometric parameters WC, WHR, WHtR is also higher in the study population. Overweight and obesity are important determinants of health leading to adverse metabolic changes, including increase in blood pressure. Being overweight and obese is associated with two to four-fold increase in the risk of developing prehypertension and hypertension as seen in Table -2 . Hence, Pre-hypertension was found to be higher among study population due to their elevated anthropometric parameters i.e. WC, WHR and WHtR. This could be due to their sedentary lifestyle, less physical activity, high salt intake and high fat intake in diet and hereditary factors. Therefore, nutritional intervention in the form of diet education and weight monitoring need to be introduced to reduce obesity.

In the present study, BMI, WC, WHR and WHtR are correlated significantly with systolic and diastolic blood pressure in both groups (Table -3).This study is similar to study done on Norfolk cohort study done by Canoy and Folsom ${ }^{17,18}$ in which they observed that waist and hip circumferences were positively correlated to systolic and diastolic blood pressure. Another study done to investigate the relationship between anthropometric indices and blood pressure showed that WHR and BMI had a linear relationship with blood pressure. ${ }^{19} \mathrm{BMI}$, WHtR and WC are the significant predictors of blood pressure in baniya and jats females of Punjab according to Table $-4,5$. Various previous studies on anthropometric parameters concluded that WC is a common measure of central adiposity and is strongly related to various coronary risk factors including blood pressure. ${ }^{1}$ Significant sex differences in regional adiposity and blood pressure, irrespective of BMI was observed among young Bengalee adults of Kolkata. WC was found to be much more 
strongly correlated than BMI with SBP and DBP in both the sexes. ${ }^{20}$

In another study done on Kayastha population of Bengal high prevalence of obesity was observed. BMI, Wc, and WHtR was strongly correlated with DBP and mean arterial pressure. Using stepwise regression analysis, it was observed that all anthropometric parameters play role in high blood pressure. ${ }^{21}$ BMI and WHR are used to assess body fat distribution. WHR has been shown to be a better indicator of intra-abdominal fat ${ }^{22}$ and coronary artery disease, than BMI. $^{23}$ It is less dependent on body size and height (Welborn ${ }^{24}$ et al), but more on hip circumference, which is an index of muscle mass (James, ${ }^{25}$ 1996).Waist circumference has been recommended for the population groups and individuals with different body builds (Welborn ${ }^{24}$ et al, 2003). WHtR is an important index of central obesity. It is free from any bias due to hip width changes along with waist circumference of short and tall subjects. Mohsen et al reported that significant correlation was found between waist: height ratio and hypertension, diabetes mellitus and metabolic syndrome particularly in women. Waist circumference cut-offs were higher for women than men for hypertension, diabetes mellitus, and dyslipidemia. ${ }^{26}$

The health risks associated with increasing BMI are continuous and the interpretation of BMI gradings in relation to risk may differ for different populations. In recent years, there was a growing debate on whether there are possible needs for developing different BMI cut-off points for different ethnic groups due to the increasing evidence that the associations between BMI, percentage of body fat, and body fat distribution differ across populations and therefore, the health risks increase below the cut-off point of $25 \mathrm{Kg} / \mathrm{m}^{2}$ that defines overweight in the current WHO classification. ${ }^{27}$ Further, Indians also tend to have excess body fat, abdominal and truncal adiposity. For any given waist circumference, they have increased body fat accumulation and for any given body fat, they have increased insulin resistance. ${ }^{28}$ These features have been referred to as the "Asian Indian Phenotype or Paradox". ${ }^{29}$

\section{CONCLUSIONS}

Blood pressure levels are related to adiposity (both general and abdominal). A significant positive correlation was observed between all derived anthropometric indices (BMI, WC, WHtR) and blood pressure (SBP and DBP) among study groups. BMI, WHtR and WC are the significant predictors of blood pressure in baniya and jat females of Punjab. Assessment of these predictors should be considered when screening people at risk for hypertension in north Indian females. Also, increased public awareness regarding intake of proper diet, weight monitoring, and screening programmes are the keys of successful prevention of hypertension.

\section{REFERENCES}

[1] Seidall JC, Kahn HS, Williamson DF, et al. Report from a centres for disease control and prevention workshop on use of adult anthropometry for public health and primary health care. Am J Clin Nutr 2001;73(1):123-6.

[2] Ness-Abramof R, Apovian CM. Waist circumference measurement in clinical practice. Nutrition in Clinical Practice 2008;23(4):397-404

[3] Ho SC, Chen YM, Woo JL, et al. Association between simple anthropometric indices and cardiovascular risk factors. Int J Obes Relat Metab Disord 2001;25(11):168997.

[4] Han TS, McNeill G, Seidell JC, et al. Predicting intraabdominal fatness from anthropometric measures: the influence of stature. Int J Obes Relat Metab Disord 1997;21(7):587-93.

[5] Despres JP, Lemieux I, Prud'homme D. Treatment of obesity, need to focus on high risk abdominally obese patients. British Med J 2001;322(7288):716-20.

[6] Balinga RR, Narula J. Salt never calls itself sweet. Indian J Med Res 2009;129(5):472-7.

[7] Kearney PM, Whelton M, Reynolds K, et al. Global burden of hypertension: analysis of worldwide data. Lancet 2005;365(9455):217-23.

[8] Shanthirani CS, Pradeepa R, Deepa R, et al. Prevalence and risk factors of hypertension in selected South Indian population - the Chennai Urban Population Study. Jassoc Physicians India 2003;51:20-7.

[9] Stamler J. Epidemiologic findings on body mass and blood pressure in adults. Ann Epidemiol 1991;1(4):34762.

[10] Belahsen R, Mziwira M, Fertat F. Anthropometry in women of childbearing age in morocco: body composition and prevalence of overweight and obesity. Public Health Nutr 2004;7(4):523-30.

[11] Sergeant LA, Bennett FI, Forrester TE, et al. Predicting incident diabetes in Jamaica: the role of anthropometry. Obes Res 2002;10(8):792-8.

[12] Nahar NS, Dubey A, Joshi A, et al. Association of anthropometric indices of obesity with diabetes, hypertension and dyslipidemia: a study from central India. Indian J Med Specialities 2012;3(1):6-11.

[13] Jimoh KA, Adediran OS, Agboola SM, et al. A study of correlation between derived and basic anthropometric indices in type 2 diabetes mellitus. Eur J Sci Res 2009;36(3):437-44.

[14] Snehlata C, Vishwanathan V, Ramachandran A. Cut-off values for normal anthropometric variables in Asian Indian adults. Diabetes Care 2003;26(5):1380-4.

[15] Hsieh SD, Yoshinaga H, Muto T. Waist-to-height ratio, a simple and practical index for assessing central fat distribution and metabolic risk in Japanese men and women. Int J Obes Relat Metab Disord 2003;27(5):610-6.

[16] Chobanian AV, Bakris LG, Black HR, et al. The seventh report of the Joint National Committee on the prevention, detection, evaluation and treatment of high blood pressure: The JNC 7 report. JAMA 2003;289(19):2560-72.

[17] Canoy D, Luben R, Welch A, et al. Fat distribution, body mass index and blood pressure in 22,090 men and women in the Norfolk cohort of the European 
Prospective Investigation Into Cancer and Nutrition (EPIC-Norfolk) study. J Hypertens 2004;22(11):2067-74.

[18] Folsom AR, Burke GL. Ballew C, et al. Relation of body fatness and its distribution to cardiovascular risk factors in young Black and Whites. The role of Insulin. Am J Epidemiol 1989;130(150):911-24.

[19] Sanya AO, Ogwumike OO, Ige AP, et al. Relationship of waist-hip-ratio and body mass index to blood pressure of individuals in Ibadan North Local Government. AJPARS 2009;1(1):7-11.

[20] Bhadra M, Mukhopadhyay A, Bose K. Adiposity, central body fat distribution and blood pressure among young Bengalee Adults of Kolkata, India: sexual dimorphism. J Physiol Anthropol Appl Human Sci 2002;21(6):273-6.

[21] Sarkar D, Mondal N, Sen J. Obesity and blood pressure variations among the Bengali Kayastha population of North Bengal, India. J Life Sci 2009;1(1):35-43.

[22] Lemieux B, Prud'homme D, Bouchard C, et al. A single threshold value of waist girth identifies normal weight and overweight subjects with excess visceral adipose tissue. Am J Clin Nutr 1996;64(5):685-93.

[23] Ohlson LO, Larson B, Svardsudd K, et al. The influence of body fat distribution on the incidence of diabetes mellitus. 13.5 years follow up of participants in the study of men born in 1913. Diabetes 1985;34(10):1055-8.

[24] Welborn TA, Dhaliwal SS, Bennet SA. Waist-hip-ratio is the dominant risk factor predicting cardiovascular death in Australia. Medical J Australia 2003;179(11-12):580-5.

[25] James WPT. The epidemiology of obesity. In: Chadwick, DJ, Cardew G, eds. The origin and consequences of obesity. (Ciba Foundation Symposium 201). Cichester: John Wiley 1996: p. 1-16.

[26] Azimi-Nezhad M, Ghayour-Mobarhan M, Safarian M, et al. Anthropometric indices of obesity and the prediction of cardiovascular risk factors in an Iranian Population. The Scientific World Jour 2009;9:424-30.

[27] BMI classification. World Health Organization. (http://www.who.int/bmi/index.jsp? Intro Page= intro_3.html.

[28] Chandalia M, Abate N, Garg A, et al. Relationship between generalized and upper body obesity to insulin resistance in Asian Indian men. J Clin Endocrinol Metab 1999;84(7):2329-35.

[29] Joshi SR. Metabolic syndrome - emerging clusters of the Indian phenotype. J Assoc Physicians India 2003;51:4456. 